\title{
Erratum to: Development and validation of a novel-based combination operational air quality forecasting system in Greece
}

\author{
Stamatis Zoras • Vasilis Evagelopoulos • \\ Ioannis Pytharoulis - Athanasios G. Triantafyllou • \\ Ioannis Skordas · Georgios Kallos
}

Published online: 10 May 2014

(C) Springer-Verlag Wien 2014

\section{Erratum to: Meteorol Atmos Phys \\ DOI 10.1007/s00703-010-0058-z}

The authors A.G. Triantafyllou and I. Skordas were omitted from this paper by mistake. The correct author list including affiliations is as follows:

Stamatis Zoras, Vasilis Evagelopoulos, Ioannis Pytharoulis, Athanasios G. Triantafyllou, Ioannis Skordas and Georgios Kallos

Stamatis Zoras, Vasilis Evagelopoulos, Athanassios G. Triantafyllou and Ioannis Skordas

Laboratory of Atmospheric Pollution and Environmental Physics, Technological Education Institute of Western Macedonia, 50100 Kozani, Greece

Email: v.evagelopoulos@gmail.com

The online version of the original article can be found under doi:10.1007/s00703-010-0058-z.

S. Zoras · V. Evagelopoulos ( $₫)$ · A. G. Triantafyllou •

I. Skordas

Laboratory of Atmospheric Pollution and Environmental

Physics, Technological Education Institute of Western

Macedonia, 50100 Kozani, Greece

e-mail: v.evagelopoulos@gmail.com

I. Pytharoulis

Department of Meteorology-Climatology, School of Geology,

A. U. Th., 54124 Thessaloniki, Greece

G. Kallos

Atmospheric Modeling and Weather Forecasting Group,

School of Physics, University of Athens, 15784 Athens, Greece
Ioannis Pytharoulis

Department of Meteorology-Climatology, School of Geology, A. U. Th., 54124 Thessaloniki, Greece

Georgios Kallos

Atmospheric Modeling and Weather Forecasting Group, School of Physics, University of Athens, 15784 Athens, Greece 